\title{
FENOMENOLOGÍA
}

\section{DUNAS DE SEDA}

Concepción Fernández González. Madrid

Finalista Premio «Vida y Salud»

Tú aún no lo sabes, pero te acaban de cortar un pecho. Y si lo supieras, probablemente, tu primera reacción sería de sorpresa. No tienes más que treinta años y has sido siempre una mujer saludable. Ni siquiera cuando te notaste el bulto se te pasó por la cabeza que aquello pudiera tener mayores consecuencias. No es que seas una mujer optimista, pero pensaste que las desgracias siempre les ocurrían a los otros. El día antes de la operación todavía insistías en que no iban a ser más que tres puntos de sutura y la extracción de una bolita diminuta que se había empeñado en molestarte en un costado. Tan convencida estabas de la insignificancia del proceso que ni siquiera se lo contaste al hombre de negocios con el que sales y te inventaste un viaje de trabajo con el que justificar tu ausencia. Fue entonces cuando te diste cuenta de que después de nueve meses aún no sabías si te amaba y que todo lo que conocías de vuestra relación era que lo pasábais bien juntos. A lo mejor, si las cosas entre vosotros hubieran sido diferentes le hubieras pedido que te acompañara al hospital y que estuviera a tu lado cuando despertases de la anestesia; a lo mejor si las cosas hubieran sido diferentes entre vosotros le hubieras confesado, y al hacerlo, te lo hubieras confesado a ti misma, que tenías miedo. Pero no fue así y todavía al entrar en el quirófano bromeabas con el cirujano sobre cómo ibas a provocar a tu pareja con aquella cicatriz en un sitio tan excitante. Recuerda que el cirujano, al oírte, dejó de mirarte durante un instante como a una paciente con un número de historia y lo hizo como lo hacen los hombres cuando pasas por su lado. Fue la última satisfacción a tu vanidad femenina antes de que la química te sumergiera en los brazos de la nada.
Ha entrado un médico en la habitación, pero permaneces en silencio. No estás dormida, sin embargo desde que despertaste de la anestesia has actuado como si lo estuvieras. El médico se ha acercado y te ha tomado el pulso, tú te has movido un poco y luego te has vuelto a quedar quieta. El médico ha parecido tranquilizarse al escuchar tu latido y ha salido de la habitación sin hacer ruido. La habitación es amplia y está llena de luz, aunque vacía de flores, de regalos y de visitas.

Hace tan sólo quince días disfrutabas de un crucero por el Adriático. Tu hombre de negocios te acompañaba y tomabas el sol, completamente desnuda, sin importarte que pudieran verte los marineros. Tú eres así, no tienes pudor, aunque no lo haces por malicia, sino por inocencia. Tus senos, hermosos aun sin el maquillaje que te ponen para las fotografías, parecían estar en aquel momento tan lejos de la mesa de operaciones como lo están los planetas. Entonces todavía pensabas que extraerte aquel bulto era como extraerte una muela. Poniendo por excusa que el sol te había quemado, pudiste evitar más tarde, cuando hiciste el amor con el hombre de negocios, que te tocara con pasión el seno izquierdo. Últimamente te dolía hasta cuando te rozaba la blusa. Del sujetador, hacía ya meses que habías prescindido, aunque no te hacía falta. Tus senos, erguidos siempre, no precisaban de andamios que les dieran la consistencia que ya tenían. Al hombre de negocios le excitaba acariciar tu ropa y notar inmediatamente tu pezón erecto e incitante. Tú aprovechabas esta circunstancia para provocarle intencionadamente en los lugares más inapropiados y él tenía que ir a refrescarse al baño porque tus senos le convulsionaban.

Te has colocado boca arriba en la cama y te observas el tórax. Al notar tu parte derecha más elevada que la izquierda levantas la ropa de la cama cor la mano y la colocas formando un montículo all donde falta. Luego, pareces satisfecha del resultadc y cierras de nuevo los ojos. El sol entra deslum. brante por la ventana y se estrella contra la puerta 
derramándose por las paredes y el suelo. Un rayo salpica la colcha y la atraviesa a la altura del montículo que acabas de formar.

En ningún momento te dijeron que tuvieran que cortarte un pecho. Te hablaron de una estancia en el hospital, de la anestesia, de una pequeña intervención quirúrgica, pero nunca de que iban a quitarte una parte de tu cuerpo a la que siempre habías sacado tanto partido. En realidad, no es que tú quisieras que te quitaran nada, pero si hubieras podido elegir, tu pecho hubiera sido lo primero que respetaras. Podrías haber prescindido de un riñón (tienes dos) o de un pulmón (también son pares), o de la vesícula (que le falta a mucha gente), o de cualquier órgano -aunque más vital-interno, pero de un seno no, de eso no hubieras prescindido nunca.

El primer trabajo que conseguiste como modelo fue gracias a unas fotografías en las que mostrabas tu pecho moreno, brillando por el aceite bronceador y con gotas salinas resbalando sobre su contorno. $\mathrm{El}$ patrocinador quedó prendado de aquellas turgencias perfectas en tamaño y forma y te contrató para anunciar, durante cinco años, un aceite bronceador de marca diferente a la que llevabas en las fotografías. De eso hacía ya mucho tiempo. Después no renovaste el contrato porque tus senos apuntaban más alto para lucir sobre ellos sutiles ropas de grandes firmas.

Ha entrado una enfermera y te ha cambiado el frasco de suero que gotea a tu brazo ligeramente inflamado. No te has dado cuenta porque ahora sí estás dormida. Luego ha bajado la persiana para evitar que la claridad que entra pueda perturbar tu sueño. Se ha fijado en la revista que dejaste sobre la mesilla antes de entrar al quirófano y ante tu sonrisa de chica de portada ha movido la cabeza con disgusto. Se ha acercado a la cama, ha estirado la ropa y ha deshecho, sin saberlo, el montículo que tan cuidadosamente tú formaras.

Tú aún no lo sabes, pero no podrás volver a ponerte tus finos vestidos de seda, algunos casi transparentes, sin nada debajo. Seguramente, también tendrás que dejar al hombre de negocios, o quizás él te deje a ti cuando vaya a rozar con la yema de su dedo tu pezón izquierdo y se dé cuenta de que ya no está. Si te decides a dejarle será fácil decirle que ya no le amas, sobre todo, porque no estás segura de haberle amado nunca. Si se decide él, el proceso será el mismo. Sin embargo, te será más difícil romper con la casa de modas para la que trabajas. Con ella sí que te une una relación sentimental mucho más fuerte que la laboral, pero de todas formas, tendrás que hacerlo. ¿Cómo van a diseñar modelos en los que ser asimétrica no tenga importancia?

Vuelve a entrar el médico y te encuentra despierta y encogida en la cama por los miles de alfileres que se te clavan en la parte izquierda del tórax. Lleva en la mano una jeringuilla que aplica a tu brazo empujando después el émbolo. El líquido que contiene penetra con suavidad en tu vena $y$, tras unos instantes, empiezas a dejar de sentir los alfileres y el dolor huye de la habitación dejándote sumergida en una dulce somnolencia.

Sueñas que eres una estatua colocada en una hornacina de un famoso museo. Los visitantes entran y se detienen delante de ti a contemplarte con admiración. Te hacen fotografías y asienten con la cabeza, mientras leen un catálogo que sujetan entre sus dedos. Hay uno, con aspecto de entendido, que te examina con más atención que el resto. Parece satisfecho de lo que ve, sin embargo antes de marcharse le oyes decir: «qué pena que una obra tan perfecta esté amputada». Esta última palabra se repite por las salas del museo como un eco. Te miras y no ves que te falte nada. Quieres gritarle que se equivoca, que estás completa, pero eres una estatua y no tienes voz. Los visitantes siguen entrando y deteniéndose a contemplarte. El hombre que acaba de hablar se aleja lentamente por el pasillo.

Me has despertado en medio de la noche gritando, o eso te ha parecido. Tu cara está húmeda y tus dedos agarrotados. No te atreves a moverte porque dudas si podrás hacerlo. Tardas un rato en descorrer el velo de tu mente y en reconocer el lugar en el que te encuentras. Todavía no has tenido el valor de tocarte, pero estás pensando en ello. Durante unos minutos continúas estática, sólo el corazón te late tan deprisa que te hace daño su latido. Tomas aire dos veces seguidas y a la tercera inspiración llevas tus dedos temblorosos a tu seno vacío. 